Methods In-depth interviews were conducted with sixteen purposively selected (based on HIV status, ethnicity, age, area, and type of sex work) female sex workers in Goa, India (December 2004-December 2005). We interrogated the life narratives to explore the nexus between the social context/risk environment and selfefficacy/agency.

Results The narratives showed a dynamic interplay between underlying vulnerabilities, precipitating factors, and the route through which women gain entry into the sex trade: The ubiquitous mitigating theme that emerged was violence in childhood and youth. This ranged from dysfunctional and violent family life, sexual violence, and violence from intimate male partners. The other underlying vulnerabilities that emerged from the narratives were also manifestations of gender disadvantage, namely being unwanted; sexual naïveté and young marriage/sexual initiation; repression of sexuality, desire and entrapment in loveless marriages; and lack of life skills and low self-esteem. The loss of social support through bereavement, abandonment or financial need, were the commonest events that precipitated entry into sex work. Becoming a sex worker was frequently an expression of agency in a context with few other economically viable choices for women. The clearest division in the route into sex work was between traditional castebased sex workers (devadasi) and those who were either introduced by peers, or sold through a broker; however the underlying and precipitating factors for both routes were remarkably similar. Mostly, initiation was described as a complex process that was mediated through peers.

Conclusion The interplay between caste, economy, gender, and violence drives the initiation into sex work, which is one of the few viable choices for the women. HIV prevention interventions therefore need to work upstream to impact upon the context within which women enter sex work and downstream to strengthen their agency. The peers who introduce women into sex work are potentially important vehicles to deliver "HIV prevention services and reduce the adverse health outcomes of sex work."

\section{P2-S2.07 IMPROVING SEXUALLY TRANSMITTED INFECTIONS (STI) PREVENTION STRATEGIES: FACTORS ASSOCIATED WITH STIS AMONG FEMALE SEX WORKERS IN INDIA}

doi:10.1136/sextrans-2011-050108.303

${ }^{1} \mathrm{P}$ Narayanan, ${ }^{1} \mathrm{~A}$ Das, ${ }^{1} \mathrm{~A}$ Gurung, ${ }^{2} \mathrm{P}$ Parimi, ${ }^{3} \mathrm{G}$ Rao, ${ }^{3} \mathrm{~A}$ Risbud. ${ }^{1} \mathrm{FHI}$, New Delhi, India; ${ }^{2}$ India HIVIAIDS Alliance, Hyderabad, India; ${ }^{3}$ National AIDS Research Institute, Pune, India

Background Studies among high-risk groups (HRGs) have shown that the presence of STIs is associated with certain demographic and behavioural characteristics as well as exposure to HIV/STI prevention interventions. The objective of this study was to understand the correlates of STIs in female sex workers (FSWs) in India in order to improve STI programming for HRGs.

Methods During 2008-2009, 417 female sex workers were recruited from three STI clinics in two cities of India as part of an operations research to evaluate the effectiveness of STI prevention service package for sex workers under Avahan, the India AIDS Initiative of the Bill \& Melinda Gates Foundation. Behavioural and clinical information along with biological samples were collected. Bivariate analysis of demographic and behavioural characteristics associated with the prevalence of common bacterial STIs- Neisseria gonorrhoeae, Chlamydia trachomatis, Treponema pallidum and Trichomonas vaginalis from the baseline data is presented in this paper.

Results At baseline $49.2 \%$ of the participants had a laboratory confirmed diagnosis for at least one of the four bacterial STIs. The significant factors associated with STI prevalence among FSWs were: inability to read or write $(\mathrm{OR}=2.2, \mathrm{p}=0.002)$; not staying with a sexual partner $(\mathrm{OR}=1.5, \mathrm{p}=0.036)$; typology of sex work: home-/hotel-based $(\mathrm{OR}=2.5, \mathrm{p}=0.038)$ vs brothel-based and streetbased $(O R=3.1, p=0.004)$ vs brothel-based; regular or occasional consumption of alcohol $(\mathrm{OR}=1.9, \mathrm{p}=0.002)$; poor knowledge of STI symptoms $(\mathrm{OR}=1.6, \mathrm{p}=0.017)$; low self-risk perception for acquiring STIs $(\mathrm{OR}=1.6, \mathrm{p}=0.031)$; less than 2 years in sex work $(\mathrm{OR}=1.8, \mathrm{p}=0.008)$; no prior exposure to HIV/STI interventions $(\mathrm{OR}=2.0, \mathrm{p}=0.001)$; and no STI check-ups in the past 6 months ( $\mathrm{OR}=1.5, \mathrm{p}=0.029)$ see Abstract P2-S2.07 Table 1.

Conclusions HIV/STI prevention programs for FSWs in India need to prioritise services for HRGs who have characteristics associated with STI prevalence. Additionally, awareness activities should promote the importance of regular STI check-ups, recognition and early treatment for STI symptoms.

Abstract P2-S2.07 Table 1 Factors associated with sexually transmitted infections among female sex workers in India

\begin{tabular}{lll}
\hline Factors & OR 95\% Cl & p value \\
\hline Illiterate (can not read or write) & $2.2(1.3$ to 3.7$)$ & 0.002 \\
Not staying with a sexual partner & $1.5(1.0$ to 2.4$)$ & 0.036 \\
Typology & & \\
$\quad$ Brothel-based & Reference & \\
$\quad$ Home/hotel-based & $2.5(1.0$ to 6.7$)$ & 0.038 \\
$\quad$ Street-based & $3.1(1.3$ to 7.7$)$ & 0.004 \\
Consume alcohol (regularly or occasionally) & $1.9(1.2$ to 2.8$)$ & 0.002 \\
Poor knowledge of STI symptoms & $1.6(1.1$ to 2.4$)$ & 0.017 \\
Low self-risk perception for acquiring STIs & $1.6(1.0$ to 2.5$)$ & 0.031 \\
New to sex work (less than 2 years) & $1.8(1.1$ to 2.8$)$ & 0.008 \\
No prior exposure to STI/HIV interventions & $2.0(1.3$ to 3.0$)$ & 0.001 \\
No STI check-ups in past 6 months & $1.5(1.0$ to 2.3$)$ & 0.029 \\
\hline
\end{tabular}

\section{P2-S2.08 CHANGING PATTERNS AND DRIVERS OF MIGRATION AMONG FEMALE SEX WORKERS OF NORTHERN KARNATAKA TO LARGE CITIES OF MAHARASHTRA, INDIA IN THE CONTEXT OF HIV/AIDS}

doi:10.1136/sextrans-2011-050108.304

${ }^{1} \mathrm{~S}$ Halli, ${ }^{1} \mathrm{~J}$ Blanchard, ${ }^{2} \mathrm{P}$ Bhattacharjee, ${ }^{2} \mathrm{~T}$ Raghavendra, ${ }^{1} \mathrm{~S}$ Moses. ${ }^{1}$ University of Manitoba, Winnipeg, Canada; ${ }^{2}$ Karnataka Health Promotion Trust, Bangalore, India

Background and Objectives The large number of FSWs from the rural areas of Northern Karnataka's three districts namely Bagalkot, Belgaum and Bijapur ( $3 \mathrm{~B}$ districts) who migrate and work in Maharashtra cities particularly in Solapur, Poona, Bhiwandi and Mumbai in brothels and lodges. In this corridor" of migration and interconnected HIV epidemics, an attempt is made in this paper to specifically address the following objectives: 1 . To assess the volume of sex worker migration from different sites and its annual turnover. 2. To describe the patterns of sex worker migration to and from the three districts of northern Karnataka and the large urban centres of Maharashtra

Methods Mapping was conducted following enumeration of the units; visited each unit (brothels and in some areas also lodges and/ or dhabas) where we had prior information that sex work was conducted and interviewed the unit manager (ie, brothel madam, lodge/ dhaba manager). The manager provided information regarding: the number of FSWs working in the unit at the timetotal number, FSWs from Karnataka, FSWs from the $3 \mathrm{~B}$ districts; number of FSWs from the $3 B$ districts that worked in the unit in the previous year and how many of them had moved to another unit in the same area. Moreover, managers provided the place of origin, age 